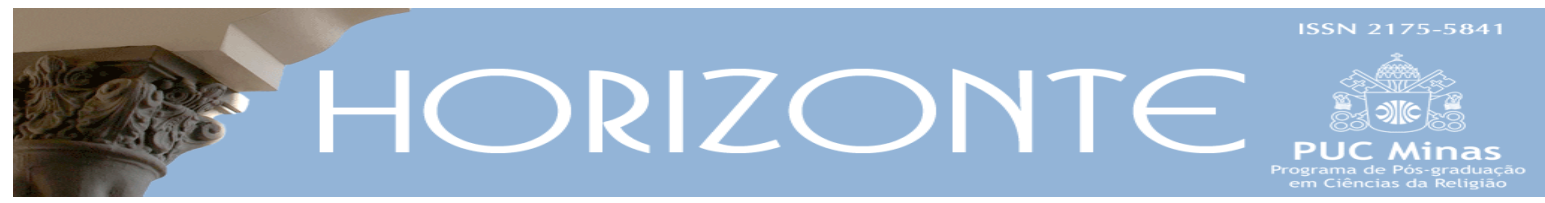

Dossiê: Islamismo: religião e cultura - Artigo original (9) $(\Theta \Theta \Theta$

DOI - 10.5752/P.2175-5841.2015v13n38p733

\title{
Islã: práticas religiosas e culturais
}

\author{
Islam: religious and cultural practices
}

Vera Lúcia Maia Marques*

\begin{abstract}
Resumo
O texto propõe uma narrativa que demonstra como as fronteiras entre a religião e a cultura são fluidas, tendo como ponto de partida as observações, por mim realizadas, na comunidade islâmica em Portugal e que aqui construo a partir de excertos de minha tese de doutorado. Ainda que pesem as divergências e as complexidades do grupo de muçulmanos em Portugal, devido às suas procedências, vertentes islâmicas e movimentos, serão os muçulmanos guineenses os protagonistas nesse artigo por se tratar de um caso de migração contínua naquele país, resultando num aumento dessa população em Portugal. E que, de certa maneira, vem exemplificar a fluidez das relações religião/ cultura, pelas próprias práticas advindas de suas culturas particulares. E mais, como maioria muçulmana procedente de uma mesma região geográfica, reproduzindo traços étnicos, sofrem um processo de segregação, não somente da sociedade mais ampla de acolhimento mas também do grupo religioso islâmico estabelecido em Portugal, o que vem gerar uma situação de conflito.
\end{abstract}

Palavras-chave: Islã; muçulmanos; práticas; cultura; religião.

\begin{abstract}
This is a narrative that shows the fluid border between religion and culture, from my own observation at the islamic community in Portugal that belongs to my doctoral thesis. Despite the differences and complexities found in the group of Muslims in Portugal, due to its origins, to Islamic movements and strands, the Guinean Muslims will be the protagonists in this article, especially because it is a case of continuing migration in that country, which results in increase of that population in Portugal. In a way, this finding helps illustrate the fluidity of relationships religion / culture, by the very practices from their particular cultures. In addition, as a Muslim majority, which comes from the same geographical region, reproducing ethnic traits, undergo a process of segregation, not only by the wider host society but also by the Islamic religious group based in Portugal, which is generating a conflict situation.
\end{abstract}

Keywords: Islam; Muslims; practice; culture; religion.

\footnotetext{
Artigo recebido em 29 de março de 2015 e aprovado em 26 de junho de 2015.

* Doutora em sociologia. Pesquisadora do Centro de Estudos da Religião Pierre Sanchis (UFMG-Brasil). País de origem: Brasil. E-mail: verinhamarques@terra.com.br.
}

Horizonte, Belo Horizonte, v. 13, n. 38, p. 733-749, abr./jun 2015 - ISSN 2175-5841 


\section{Introdução}

Diante do cenário nacional e internacional, onde acadêmicos, comunidades islâmicas, imprensa, órgãos governamentais e outros vêm discutindo questões relativas ao Islã, muçulmanos e o seu crescimento em todo o mundo, creio ser oportuna a apresentação deste artigo, que traz parte das minhas observações do campo de pesquisa, que resultou na minha tese de doutorado concluída na Universidade Federal de Minas Gerais.

O projeto da pesquisa de doutorado deu-se em função da vontade de estender os meus conhecimentos sobre o tema. Anteriormente, na pesquisa de mestrado, abordei as conversões de brasileiros ao Islã. Foi uma etnografia realizada em São Paulo e sua região metropolitana, onde procurei na biografia dos meus pares compreender as suas trajetórias pessoais, suas motivações, dificuldades e facilidades antes, durante e após a conversão. A pesquisa de doutorado visou comparar as práticas religiosas e culturais islâmicas no Brasil e em Portugal, tanto dos muçulmanos de origem, ou seja, os "nascidos muçulmanos" como os "novos muçulmanos por conversão", tomando nota dessa rica e complexa tessitura de relações entre religião e cultura.

A escolha de Portugal deu-se por conta da presença do catolicismo, como matriz cultural nos dois países, pela presença dos muçulmanos de origem moura e de escravos africanos muçulmanos, trazidos pelos colonizadores portugueses, e pelo interesse na ampliação e na intensificação dos diálogos acadêmicos entre Brasil e Portugal. Mas não somente. Portugal apresenta uma diversidade étnica e cultural que faz do grupo de muçulmanos uma interessante mistura de práticas religiosas.

Em Portugal, os muçulmanos de origem “indo-moçambicana” predominam não por representarem a maioria, já que atualmente o número de muçulmanos 
guineenses é superior, mas por serem a liderança. Além da diversidade de procedência que compõe o contexto islâmico português, as vertentes islâmicas (sunitas, xiitas Ismaili Nizari, xiitas Isna Ashari, Ahmadia, Bahái), os movimentos (Wahhab, Salafi, Tabligh Jamaat) e as diferentes práticas religiosas (como os milads ou celebrações), ajudam a compor uma gama de variantes, que resulta num universo complexo. Comparativamente, a maioria muçulmana que se encontra no Brasil resulta da imigração de libaneses, de sírios e de palestinos. Portanto, são os "árabes" no Brasil que detêm a liderança, não somente pelas questões sócio-econômicas mas, neste caso, por serem também a maioria. Vale ressaltar que, atualmente, encontram-se no Brasil outros grupos menores de imigrantes - africanos, asiáticos, dentre outros. Além disso, outro perfil tem se delineado, pelo crescimento do número de convertidos, inclusive de jovens negros das periferias de cidades brasileiras que divulgam o Islã pelo rap e hip-hop.

Voltando ao campo islâmico português, onde focarei a minha narrativa, alguns são os fatores de diferenciação que influenciaram as subdivisões entre os muçulmanos naquele país. As questões sócio-econômicas e a região geográfica de origem determinaram as relações de poder entre os grupos. Foi o que percebi enquanto estive entre os muçulmanos portugueses ${ }^{1}$.

Preliminarmente, podemos dizer que os grupos linguísticos e similaridades ritualísticas na vida religiosa alicerçam sentimentos de afinidade. Também as afinidades de origem e procedência comum são importantes nas relações desses grupos afins. Assim, os tipos de pertencimento podem ser definidos, grosso modo, como culturais e religiosos. No primeiro tipo, a título de exemplo, o Islã pode ser visto como parte de um sistema cultural, sendo adotadas mais, ou menos, normas de conduta das sociedades seculares. Entretanto, alguns ritos são seguidos como uma obrigação religiosa e/ou como prática cultural e as práticas culturais

\footnotetext{
${ }^{1}$ Foram seis meses, devido a uma "bolsa sanduíche" concedida pela CAPES-MEC (Coordenação de Aperfeiçoamento de Pessoal de Nível Superior - Ministério da Educação), em cooperação com a Universidade Nova de Lisboa. Contei com a co-orientação da professora Dra. Susana Pereira Bastos, além da professora Dra. Léa Freitas Perez, minha orientadora na UFMG.
} 
implicam certas particularidades. Portanto, a despeito de discussões que passam pela universalidade do Islã, existem interpretações e práticas que originaram formas diversas de religiosidades.

AbdoolKarim Vakil, intelectual muçulmano português, de origem indomoçambicana, professor do King's College London nos apresenta o Islã como uma religião universal. Para ele, o Islã não é uma cultura, e "como religião será sempre vivida em contextos culturais específicos aos quais se adapta” . Todavia,

quando a cultura, a linguagem, os ritos, as práticas, a inter-relação local, geram características fortes e reconhecíveis na vivência ou no discurso islâmico, como no caso do Islão africano, do Islão do subcontinente asiático, do Sudeste Asiático, do Irão, da Turquia, por exemplo, é comum designá-lo por esses termos (VAKIL apud COELHO; ROCHA, 2005, p. 183 - grifo meu).

Seguindo essa linha de raciocínio, se observarmos a diversidade cultural entre os muçulmanos de várias partes do mundo, é possível que enxerguemos vários Islãs. Entretanto, se olharmos mais atentamente, percebemos que, embora procedentes de distintas áreas geográficas e de culturas diversas, encontraremos entre eles os mesmos preceitos islâmicos. Portanto, para um outro intelectual muçulmano, Tariq Ramadan (2004), suíco de procedência egípcia e professor da Oxford University, só existe um Islã, e os princípios fundamentais que o definem são aqueles que todos os muçulmanos aderem. Há, no entanto, possibilidades de transformações e adaptações aos vários contextos sociais e culturais. Enfim, podemos resumir dizendo que a ummah (comunidade global de fé) conecta seus fiéis em todo o mundo. No entanto, não deve ser vista de forma indiferenciada, pois cada grupo de muçulmanos possui a sua particularidade e, consequentemente, as suas práticas religiosas e culturais. 


\section{Guineenses: espaços público / privado}

Pensar em Islã, algumas vezes, nos traz à mente os povos árabes e essa correlação está implícita na genealogia da religião. Entretanto, o mundo árabe não se resume a muçulmanos e, na atualidade, a maioria dos muçulmanos não são árabes. O mundo árabe conta com uma diversidade de tradições e de crenças: judeus, cristãos maronitas, melquitas, ortodoxos (antioquinos), siríacos, católicos romanos, protestantes.

Em pesquisa realizada em 2009 pelo Pew Research Center's Forum on Religion \& Public Life em mais de 200 países, ficou constatado que a população muçulmana no mundo consistia em 1.57 bilhões de pessoas, o que representava, na época, 23\% da população mundial, estimada em 6.8 bilhões. Mais de 60\% dos muçulmanos estariam na Ásia e cerca de 20\% no Oriente Médio e norte da África, sendo que essas duas últimas regiões teriam a maior porcentagem de países de maioria muçulmana. ${ }^{2}$ Portanto, é preciso desfazer a confusão que persiste entre "muçulmano" e "árabe” e desmistificar que o Islã é a religião dos árabes ou do Oriente Médio, embora exista uma liderança religiosa, particularmente da Arábia Saudita, centro do movimento transnacional wahhab e do Egito, centro do movimento salafi.

Diante de tal constatação, a maioria dos muçulmanos que encontra-se em Portugal não é proveniente de países árabes, mas sim da Ásia e África. Com isso, a diversidade de procedência que compõe o contexto islâmico naquele país vai além dos indo-moçambicanos e guineenses, já citados. Em Portugal encontram-se também os bangladeshianos, os paquistaneses, os marroquinos e os portugueses convertidos e grupos menores, de uma migração recente. A pesquisadora Nina Clara Tiesler esclarece-nos também que,

\footnotetext{
${ }^{2}$ O Pew Forum está baseado em Washington, D.C. Cf. PEW FORUM ON RELIGION \& PUBLIC LIFE, 2010.
} 
a filiação religiosa e o passado cultural dos imigrantes dos PALOP são diversificados: religiões (locais) africanas, paganismo e cultos sincretistas, catolicismo de influência romana e formas africanas, uma pequena percentagem de protestantismo, formas diferentes de Islão afro-cultural (incluindo grupos sufi), Islão sunita de antiga origem indiana, ismaelismo e hinduísmo. Os muçulmanos sunitas africanos vieram da Guiné-Bissau. Outros muçulmanos africanos emigraram para Portugal vindos de Moçambique. Embora haja muitos muçulmanos sunitas da África Oriental e ismaelitas (um ramo xia), ambos de origem indiana, Moçambique foi o ponto de partida da maioria dos muçulmanos que vivem actualmente em Portugal (TIESLER, 2000, p. 124)3.

Diante de tanta complexidade étnica e religiosa, nesse texto irei ater-me a um desses grupos provenientes dos PALOP, os guineenses, por se tratar de um caso de migração contínua, que resultou num aumento dessa população em Portugal e que de certa forma exemplifica a relação fluida entre a religião/cultura, modernidade/tradição.

Em princípio podemos dizer que os muçulmanos que emigraram de seus países levaram ao país de destino não apenas as memórias dos fundamentos islâmicos, mas também o seu modo de vida e seus traços étnicos. E, os guineenses destacam-se pela sua diversidade cultural, religiosa e linguística, além de subdividirem-se em várias etnias - balantas, fulas, papéis, manjacos, mandingas, beafada e outras.

Pois bem, os guineenses muçulmanos que se estabeleceram em Portugal demonstram ter padrões de valores rígidos, pois desde muito cedo adquirem orientações e preceitos religiosos rigorosos nas escolas corânicas. Mas suas práticas religiosas islâmicas, diferenciam-se das práticas religiosas dos outros muçulmanos, como os moçambicanos de origem indiana, por exemplo. Essa diferenciação resulta numa nítida separação dentro e fora do espaço religioso. Isso é visível nas orações das sextas-feiras na Mesquita Central de Lisboa, onde o colorido das roupas, os bordados dourados, os turbantes e enormes lenços

\footnotetext{
${ }^{3}$ PALOP: Países Africanos de Língua Oficial Portuguesa.
} 
combinando destacam a presença das mulheres guineenses. Além de fazerem suas orações, fazem dali um espaço de encontro social e convívio guineense.

Fora do espaço religioso, e com objetivo de ajudarem-se mutuamente, os guineenses instituíram em Portugal associações e centros culturais. Interessante se faz observar que cada grupo étnico possui as suas próprias "associações", foi o que percebi quando indaguei, a uma muçulmana, se na Associação Feminina da Mesquita Central, uma comissão de ajuda mútua das muçulmanas indomoçambicanas (em Lisboa), existiam mulheres guineenses e ela prontamente respondeu-me que elas (as guineenses) já tinham as suas associações. E isso foime confirmado posteriormente pelo coordenador da Comissção de Jovens, um muçulmano português de origem moçambicana 4 .

Diante de tal informação busquei as associações e centros guineenses para melhor entender aqueles muçulmanos. E, de fato, percebi que a Mesquita Central não era o único espaço de convívio, mas que outros espaços eram ocupados pelos guineenses como forma de ajuda e inserção. A Associação dos Muçulmanos Naturais da Guiné-Bissau, por exemplo, foi criada em 1990, e na época era dirigida pelo guineense Manso Baldé. A Associação Guineense de Solidariedade Social (AGUINENSO), fundada em 17 de Fevereiro de 1987, adquiriu considerável relevância nos movimentos políticos junto ao Estado e de outras instituições (ABRANCHES, 2007). Outras associações foram também criadas por mulheres guineenses, com objetivo de ajuda mútua: Sabú N’hima, Badin Clube, Gente Rica, Djamano-diata. Portanto, as associações são uma forma de inserção social e de superação das dificuldades encontradas nos contextos islâmico e português.

Outro espaço que encontrei, o Centro Português Árabe Pulaar e Cultura Islâmica, na Reboleira periferia de Lisboa, foi fundado em 2002, pelo guineense Bubacar Baldé5. Professor Bubacar Baldé, como era chamado entre os guineenses,

\footnotetext{
${ }^{4}$ Em entrevista que realizei, em 26 jan. 2009.

${ }^{5}$ Pulaar (Fula) é falado em 20 países africanos.
} 
foi o segundo imam da Mesquita Central de Lisboa, mas decidiu sair e fundar esse centro de cultura Fula (COELHO; ROCHA, 2005). O centro de cultura, dentre outras finalidades, cria condições para melhor integração entre os imigrantes de origem Fula e a sociedade portuguesa, sem que percam os laços com suas tradições, com a sua cultura e com a sua língua.

A distribuição geográfica dos imigrantes guineenses no espaço físico português está centrada em pequenos grupos, que alugam apartamentos, parte de casas ou quartos, por toda a área metropolitana de Lisboa, no Porto e no Algarve, ficando, dessa maneira, dispersa no espaço urbano, não existindo, portanto, um "bairro guineense". Por outro lado, há uma espécie de "territorização" do espaço urbano, onde se encontram para trocar informações, fazer suas redes de trabalhos e ajudar os que acabam de imigrar. Esses locais são o Rossio e a Praça da Figueira, espaços centrais de Lisboa, de passagem e de fácil acesso. Os guineenses os chamam de tchom di pepel, em "crioulo" ("chão de papel”), "à imagem da zona com o mesmo nome em Bissau" (MACHADO, 2002, p. 230).

Os outros espaços onde os guineenses se concentram, em Lisboa, são também o Martim Moniz, uma das zonas comerciais da cidade, onde dividem o espaço com os bangladeshianos e com os chineses. Há também a Feira do Comércio, que é realizada semanalmente e a Mesquita Central, às sextas-feiras. Embora outros africanos encontrem-se em outros pontos mais descontraídos da cidade, como bares e discotecas, os guineenses provavelmente não serão encontrados nesses locais. Em primeiro lugar, pela situação econômica e também pela religiosidade, no caso dos guineenses muçulmanos. E mais, como maioria muçulmana procedente de uma mesma região geográfica reproduzem traços étnicos mas também sofrem um processo de segregação, não somente da sociedade mais ampla de acolhimento como do grupo religioso islâmico estabelecido em Portugal. 


\section{Práticas religiosas e culturais dos muçulmanos guineenses}

No mundo contemporâneo, os modos de vida não se estruturam a partir de um "pólo unificado". A diversidade das experiências leva aos mais diversos grupos de afinidades (MAFFESOLI, 1998, pp 120-121). E o Islã, não sendo um bloco monolítico, se mantém nas diferenças étnico-culturais dos grupos muçulmanos. As (re)interpretações, a partir dos contatos fora do seu grupo, ditam o que podem (ou devem) fazer e o que não podem (ou não devem) fazer.

Numa das minhas visitas à Mesquita Central de Lisboa, ouvi de uma interlocutora: "já viu essa menina africana lá no fundo de jeans justo, sem mangas, peito descoberto e com lenço na cabeça? Ninguém sabe se ela é muçulmana, pois aquilo não é o hijab”. Pois bem, essa observação colocava em questão o conceito de hijab (véu islâmico), a discrição e o jeito de se comportar. Mas, a forma de explicar o seu uso chamou a minha atenção sobre aquela "menina africana", também muçulmana, que na visão de outros muçulmanos, não tinha um "comportamento muçulmano". É que as questões que permeiam o "ser muçulmano" são complexas, quando se misturam ao "ser muçulmano étnico".

Eu já havia percebido que algumas guineenses usavam roupas fora e dentro da mesquita que não condiziam com aquelas apresentadas no nosso imaginário ou pela mídia, salvo nas orações em que todas se cobrem com um lenço. Outras cobriam a cabeça ao estilo africano, de um jeito bem chamativo, que não lembram em nada a "modéstia" que os muçulmanos descrevem como sendo parte da religião. Como exemplo, tomo por empréstimo o depoimento concedido a Maria Abranches (2007), em sua investigação com mulheres guineenses e indomoçambicanas em Portugal, que ilustra o pensamento de uma guineense sobre o uso do hijab: 
As mulheres muçulmanas, normalmente, não devem deixar o cabelo solto, só que hoje em dia, como se vê, cada um faz como quer. Mesmo na Guiné também é assim, andamos assim. Há os que não deixam mesmo o cabelo solto, tapam tudo até aqui, mas há menos na Guiné isso do que nos países árabes. Fazem o possível por tapar o cabelo, as partes que atraem mais os homens, é isso. Mas isso, na Guiné, há pouca coisa. Quando as pessoas têm certas idades é que fazem mais isso (ABRANCHES, 2007, p. 168-169).

Esta e outras formas de pensar o Islã e suas práticas, ou talvez possamos chamar de etnização, nos instiga a considerar as integrações globais. $\mathrm{O}$ encontro das culturas como transnacional, pelos movimentos de deslocamentos em função das descolonizações, das migrações e por motivos econômicos e sociais. É a mobilidade cultural e das práticas religiosas, como vimos no caso do uso do véu e de outras práticas, como o gesto que algumas muçulmanas guineenses faziam ao entrar no local de oração reservada às mulheres. Elas colocavam a mão no chão e levavam à cabeça e ao coração, fazendo lembrar quando as filhas de santo entram num terreiro de umbanda. Além disso, elas cumprimentavam-se com as duas mãos também como nos rituais afro-brasileiro. E isso, eu nunca tinha percebido entre os outros muçulmanos.

Outras práticas, por vezes combatidas pelos outros grupos islâmicos, são os marabus, muçulmanos que estudaram o Alcorão na Guiné-Bissau, no Senegal, na Zâmbia, no Marrocos ou na Arábia Saudita e que dizem ter poderes adivinhatórios que previnem os males e as desgraças. Geralmente, são líderes espirituais e professores das escolas alcorânicas em seus lugares de procedência. São conhecidos em Portugal, principalmente na região de Lisboa e Vale do Tejo, Porto, Braga, Faro ${ }^{6}$.

Os curandeiros também são consultados pelos portugueses, independentemente de filiação religiosa. Mestre Biai é um desses marabus que atendia em Lisboa. Ele era procurado tanto pelos guineenses como pelos portugueses. Seus dotes, que Mestre Biai chama de "segredos", foram aprendidos

\footnotetext{
${ }^{6}$ Marabu é uma palavra derivada provavelmente do português «mouro», segundo Machado (2002).
} 
na Gâmbia. No entanto, ao imigrar para Portugal, esses “segredos” permaneceram adormecidos, enquanto tentava ganhar a vida trabalhando na construção civil. Com o passar do tempo resolveu retomá-los e, com eles, garantir a sua sobrevivência (COELHO; ROCHA, 2005).

Não são poucos os portugueses da classe popular que consultam os curandeiros ou marabus, muçulmanos esses que, por vezes, mal falam o português e que anunciam nas revistas, jornais ou folhetos os seus serviços como advinhos. Nas propagandas falam de algumas atribuições com finalidade de reforçarem a credibilidade dos que os procuram: "grandes e absolutos poderes", "longa experiência no ofício”, “domínio dos saberes mágicos característicos de vários países africanos - Mali, Guiné-Conacri, Senegal, Gâmbia”. São inúmeras as promessas que vão desde as soluções para o amor, negócios, exames, enfim, todo o tipo de assuntos ligados ao cotidiano e, até mesmo, algumas inovações (MACHADO, 2002, p. 261). Outros, prometem soluções dos problemas de dinheiro, problemas profissionais, vícios, doenças espirituais, maus-olhados, impotência sexual, frigidez, aproximação da pessoa amada, concorrência, concursos, sorte no jogo, investimento e muitas outras soluções. Contudo, para alguns guineenses, essa publicidade soa negativamente, pois acreditam que os bons marabus dispensam esse tipo de apelo.

Uma outra prática envolvendo cultura e religião, entre os muçulmanos africanos, é a polêmica excisão feminina (BOUHDIBA, 2006). Existe um entrelaçamento cultural entre essa prática pré-islâmica e o Islã, em alguns povos da África. O mais interessante é perceber que alguns muçulmanos guineenses já nem sabem se, de fato, existe essa prescrição no Alcorão, como pude presenciar nas $2^{a}$ s. Jornadas da língua Pulaar e cultura Fulbe a que assisti em Lisboa. Duas jovens muçulmanas levantaram a questão sobre a prescrição alcorânica da excisão feminina. A resposta de uma das expositoras levava em conta que os árabes não possuíam tais práticas. Num segundo esclarecimento, foi dito que a prática era 
anterior ao Islã, cujas referências encontravam-se no Egito (em Luxor). Uma terceira opinião reiterou essa última, de que a prática era pré-islâmica. A dúvida persistiu e houve uma tentativa de colocar um ponto final na questão. No entanto, não mais as jovens, mas outros participantes (homens e mulheres) disseram que as respostas não tinham sido claras. Finalmente, o esclarecimento partiu de um religioso que estava na platéia que explicou, em fula, não existir a prescrição da prática da excisão feminina no Alcorão. Ao final, partiu de um dos expositores a recomendação de que, mesmo que outros povos condenem seus costumes, suas tradições deveriam ser mantidas. Embora a recomendação não tenha sido claramente no âmbito da questão em debate, foi possível entendê-la como uma certa resistência da transformação das suas tradições ancestrais, como um rito de passagem, passadas de geração a geração.

Ainda sobre esse mesmo assunto, várias associações discutem essa importante questão, tanto nos países de origem dessa prática pré-islâmica como na Europa. Em Portugal, a Mûtola, tem trabalhado com essa polêmica. Essa associação nasceu depois de ter sido publicado no jornal Público, em 2002, matéria que "denunciava a prática da excisão entre os guineenses em Portugal” (COELHO; ROCHA, 2005, p. 70).

Com efeito, práticas religiosas e cultura se misturam. Segundo Luís Fernando Machado (2002), entre os guineenses existe uma interação entre as práticas pré-islâmicas, islâmicas e católicas que foram levadas pelos portugueses para a Guiné-Bissau. Um exemplo é o que chamam de "festa do sétimo dia" ou "sete", realizada no sétimo dia do nascimento de uma criança, e é destinada à sua proteção contra os espíritos maléficos. É também o dia em que ela é apresentada a toda a família, à comunidade e recebe o nome, cuja recomendação é de que "é um direito da criança ter um bom nome" (MOHAMAD, s.d., p. 76-81)7. Mas, a despeito do que considera-se como um "bom nome muçulmano", vale notar que algumas vezes o registro de nomes muçulmanos, diferencia-se naquele espaço. Primeiro,

\footnotetext{
${ }^{7}$ Sheikh Aminuddin Mohamad é presidente da Associação Islâmica de Moçambique.
} 
porque o registro de nomes em Portugal deve obedecer a uma lista de nomes portugueses, e as exceções devem ser justificadas. No caso do nome muçulmano, é necessário ter um documento da Mesquita Central confirmando a procedência islâmica. Entretanto, nem sempre o nome muçulmano apresentado pelos guineenses é reconhecido pela mesquita, dada a diferença cultural.

Além das questões acima relatadas, os festejos que sucedem o dia do casamento na mesquita, ou a cerimônia de "amarramento", como é chamada pelos guineenses, é controversa. No decorrer dessa festa, é realizada a "dança sensual” das mulheres. Descreve Abranches: "dançam desenhando movimentos sensuais, as mulheres vão levantando os vestidos, deixando ver parte das pernas e dos ombros. Os homens, porém, não penetram no espaço reservado à dança sensual das mulheres" (ABRANCHES, 2007, p. 135-136). A autora ainda diz, baseado em Boukhbza:

Tradicionalmente, sobretudo nos países do norte de África, os homens não apreciam a festa que acompanha o casamento, na medida em que consideram que pode atrair espíritos negativos quando se realiza fora do espaço religioso, conduzindo, por isso, ritos de protecção em simultâneo (BOUKHBZA apud ABRANCHES, 2007, p. 135).

Já no ritual de morte a preparação do corpo, o enterro e as cerimônias que se realizam passados os 40 dias parece não diferir entre os guineenses e os indianos, no contexto português, exceto por alguns pormenores ${ }^{8}$. O senhor Bubacar Baldé, já referido anteriormente, explicando sobre os rituais de morte, disse-me que, quando morre uma pessoa em seu país, os dias que se seguem são destinados às festas. O objetivo é consumir, literalmente, toda a "riqueza" do falecido. As pessoas comem, bebem, dançam e tocam tambores pelo tempo necessário para que tudo seja consumido. Entretanto, questiona essa prática, mas

\footnotetext{
${ }^{8}$ De acordo com conversa informal com uma muçulmana moçambicana, existem duas cerimônias: a primeira passados 3 dias do falecimento e com 40 dias.
} 
diz haver, entre os muçulmanos guineenses que vivem em Portugal, alguns resquícios.

Estas e outras práticas, algumas vezes, levam a contestações e conflitos tanto fora do grupo praticante quanto dentro do grupo. Os guineenses, por exemplo, importam práticas culturais locais, sancionadas por uns e contestadas por outros. Isso mostra as "diferenças culturais inerentes à prática do Islão, e com elas a sempre problemática questão de distinguir o que é 'islâmico' e o que é 'cultural' na religiosidade dos muçulmanos" (VAKIL, 2004, p. 308). Deste modo, embora exista um discurso de semelhança entre os muçulmanos nos contextos inseridos o que de fato se estabelece, em última instância, é a diferença na diferença. E diferença gera conflito.

\section{Considerações Finais}

Nos dias atuais, as integrações globais propiciaram o encontro das culturas e, porque não dizer, também das religiões (e suas práticas). É a ideia de cultura, como transnacional, pelos movimentos de deslocamentos em função das descolonizações, das migrações e por motivos econômicos e sociais. É a mobilidade cultural (e também das práticas religiosas), que leva a questionamentos sobre o uso do véu, do casamento e outras práticas que pude aqui descrever.

Entretanto, lembrando Pierre Sanchis 9, nas relações sociais, "os grupos não chegam às mesmas conclusões" e "eles têm em comum muitos problemas" em que “cada grupo tende a resolver do seu jeito". E é esse jeito diferente que constitui a cultura de cada um. São as escolhas que irão constituir os mundos diferentes; escolhas de acordo com valores, com significados atribuídos. Através desse universo de escolhas e de significação, o sistema cultural é constituído e cada elemento se encaixa de forma organizada. Assim, a cultura é uma criação do

\footnotetext{
${ }^{9}$ Aula inaugural proferida por Pierre Sanchis em 2007, sobre o tema Cultura Brasileira e Religião, no Programa de Pós-Graduação em Antropologia, da Universidade Federal de Minas Gerais, Belo Horizonte. 
coletivo; transmite-se e constitui uma tradição. Porém, é o indivíduo que vai transformar a cultura. É seu jeito de transmitir que confundirá com o de transformar. Outros indivíduos se oporão a essa ação transformadora, o que contribuirá com o movimento da "redescoberta das raízes" (2007, p 2-5). E pode ser deste lugar que surge o conflito.

Como nos mostra Georg Simmel (1964), o conflito destina-se à resolução dos dualismos divergentes; é um caminho para atingir alguma unidade. Além das forças de união que o conflito pode gerar, em oposição a outros grupos, Simmel reforça a ideia de que não importa qual é a diferença da configuração e do sentimento de integração, própria das competições, sempre existirão o mais forte e o mais fraco. No entanto, o antagonismo ou a concorrência desempenham papéis de integrações que serão positivos. A oposição é parte integrante da relação, resultando numa "certa comunidade entre as duas partes". Ou seja, para que exista o conflito, é necessário que exista reciprocidade (SIMMEL apud PEREZ, 2003).

Desta maneira, é exatamente dessa região conflituosa que as diferenças das práticas culturais e religiosas tornam-se contundentes, pois "o processo de heteroetnicização das minorias [...] facilita que a sociedade de acolhimento adopte uma estratégia de segregação" onde as pessoas passam a ser vistas "como pertencentes a outras raças, religiões ou etnias» (MACHADO, 2002, p. 53).

E, no caso português, os guineenses muçulmanos, maioria sunita como a maioria dos muçulmanos em Portugal, representam esta minoria, esse "outro" que também levou para esse terreno os seus ensinamentos tanto morais quanto religiosos. Suas práticas seguem a sua escola jurídica de pensamento e as suas confrarias que, de certo modo, oferecem respostas às suas ancestralidades por comportarem seus aspectos esótericos, nem sempre "legais" de acordo com outros 
muçulmanos oriundos de outras origen ${ }^{10}$. Entretanto, num espaço já marcado pela diversidade de procedência, vertentes islâmicas, movimentos e diferentes práticas religiosas, os guineenses são mais uma minoria neste universo complexo islâmico.

Enfim, ainda que o Islã não seja visto, consensualmente, como uma religião étnica, os muçulmanos carregam características particulares dos seus países de procedência, tal como os árabes no Brasil, os indo-moçambicanos ou bangladeshianos e os guineenses em Portugal. São as realidades locais de natureza cultural que atribuíram ao Islã uma conotação étnica. São as diferenças fluídas entre religião e cultura que perpassam o Islã. Mas que, sintetizando com Brigitte Marechal, as diferenças, que permeiam os vários grupos islâmicos, são consideradas [pelos muçulmanos] como um presente de Deus, daí a afirmação do “caráter espiritual e universal do Islã” (MARÉCHAL, 2003, p. 12).

\section{REFERÊNCIAS}

ABRANCHES, Maria. Pertenças fechadas em espaços abertos: estratégia de (re)construção identitária de mulheres muçulmanas em Portugal. Lisboa: Alto Comissariado para a Imigração e Diálogo Intercultural (ACIDI, IP), 2007.

BOUHDIBA, Abdelwahab. A sexualidade no Islã. São Paulo: Editora Globo, 2006.

COELHO, Alexandra Prado; ROCHA, Daniel. Muçulmanos em Portugal: onde fica Meca quando se olha de Lisboa? Lisboa: Público, 2005.

MACHADO, Fernando Luís. Contrastes e continuidades: migração, etnicidade e integração dos guineenses em Portugal. Oeiras: Celta, 2002.

MAFFESOLI, Michel. O tempo das tribos: o declínio do individualismo nas sociedades de massa. 2 ed. Rio de Janeiro: Forense Universitária, 1998.

MARÉCHAL, Brigitte. Mosques, organisations and leadership. In: MARÉCHAL, Brigitte et al. (Ed.). Muslims in the enlarged Europe. Leiden: Brill, 2003. p. 79-150.

\footnotetext{
${ }^{10}$ As quatro principais escolas sunitas de pensamento jurídico islâmico são: hanafita, malikita (presente Arábia, na África do Norte e Central, no Egito e no Sudão), shafi'ita e hanbalita, o que não exclui a existência de outras. Sobre as confrarias a Qâdiriyya ficou conhecida como uma das confrarias que contribuiu para a islamização na África, juntamente com a dos Tijânis.
} 
MOHAMAD, Amiuddin. Manual islâmico com khutbas. Maputo: Biblioteca Fiuzul Isslam, s. d.

PEREZ, Léa Freitas. Conflito religioso e politeísmo dos valores em tempos de globalização. In: PEREIRA, Mabel Salgado; SANTOS, Lyndon de A. (Org). Religião e violência em tempos de globalização. São Paulo: Paulinas, 2003. p. 53-75.

PEW FORUM ON RELIGION \& PUBLIC LIFE. Muslim Networks and Moviments in Western Europe. Pew Research Center's Forum on Religion \& Public Life. Sept. 2010. washington, D.C. Disponível em:

http://www.pewforum.org/files/2010/o9/Muslim-networks-full-report.pdf. Acesso em: 12 jan. 2015.

RAMADAN, Tariq. Western Muslims and the future of Islam. New York: Oxford University Press, 2004.

SANCHIS, Pierre. Cultura brasileira e religião. 2007 (Aula inaugural) - Mestrado em Antropologia da Religião, UFMG, Belo Horizonte.

SIMMEL, Georg. Conflict \& the web of group-affiliation. New York: The Free Press, 1964.

TIESLER, Nina Clara. Muçulmanos na margem: a nova presença islâmica em Portugal. Sociologia, Problemas e Práticas, Lisboa, n. 34, p. 117-144, 2000.

VAKIL, AbdoolKarim. Do outro ao diverso. Islão e muçulmanos em Portugal: história, discursos, identidades. Revista Lusófona de Ciência das Religiões, Lisboa, ano III, n. 5-6, p. 283-312, 2004.

SANCHIS, Joseph François Pierre. Cultura brasileira e religião. 2007. Aula inaugural no Mestrado em Antropologia da Religião, UFMG, Belo Horizonte. 